\title{
Prediction of the Population at Risk of Atherothrombotic Disease: A Three Step Approach
}

\author{
William E. Feeman, \\ Bowling Green Study, Bowling Green, Ohio, USA.
}

Corresponding Author: William E. Feeman, Bowling Green Study, Bowling Green, Ohio, USA.

Received date: December 11, 2021; Accepted date: December 25, 2021; Published date: January 04,2022

Citation: William E. Feeman, (2022) Prediction of the Population at Risk of Atherothrombotic Disease: A Three Step Approach. J. Cardiology Research and Reports 4(1); DOI: 10.31579/2692-9759/036

Copyright: (C) 2022, William E. Feeman, This is an open access article distributed under the Creative Commons Attribution License, which permits unrestricted use, distribution, and reproduction in any medium, provided the original work is properly cited.

\begin{abstract}
The mainstay of the prevention of atherothrombotic disease (ATD, which is atherosclerotic disease, with emphasis on the thrombosis that so often precipitates the acute ATD event, such as acute myocardial infarction, acute cerebral infarction, aortic aneurysm, etc) is the prediction of the population at risk of ATD. There are many predictive tools, all of which use the same general risk factors, but the one favored by the author is the Bowling Green Study (BGS) graph.. This graph is based on the ATD risk factor constellations of 870 people in Bowling Green, Ohio, the county seat of Wood County, in northwest Ohio. (There is one other patient who has full lipid data and blood pressure data, but whose cigarette smoking status is not known.) The ordinate of the graph is the lipid arm and consists of the Cholesterol Retention Fraction (CRF, defined as [LDL-HDL]/LDL). HDL refers to high-density lipoprotein cholesterol and LDL refers to low-density lipoprotein cholesterol. The abscissa of the graph is the blood pressure arm, represented by the systolic blood pressure (SBP). This graph was initially developed in 1981 (using the LDL:HDL ratio) then modified in 1983 (using the CRF), and, by 1988, the author was able to generate a threshold line, which separated the main stream of ATD patients' CRF-SBP plots from those of a few outliers. (The threshold line is not a regression line, but rather a divider, based on the principle of the fewest false negatives.) The 1988 threshold line was modified in 2000 to its present location at CRF-SBP loci $(0.74,100)$ and $(0.49,140)$. Many of the various ATD risk predictors are complex and difficult to use, whereas the graph is simple to use and based on the risk factor constellations of actual ATD patients, wherein lies its value.
\end{abstract}

Keywords: atherothrombotic disease; acute myocardial infarction; acute cerebral infarction; aortic aneurysm

\section{Introduction}

The mainstay of the prevention of atherothrombotic disease (ATD, which is atherosclerotic disease, with emphasis on the thrombosis that so often precipitates the acute ATD event, such as acute myocardial infarction, acute cerebral infarction, aortic aneurysm, etc) is the prediction of the population at risk of ATD. There are many predictive tools, all of which use the same general risk factors, but the one favored by the author is the Bowling Green Study (BGS) graph. [1-11]. This graph is based on the ATD risk factor constellations of 870 people in Bowling Green, Ohio, the county seat of Wood County, in northwest Ohio. (There is one other patient who has full lipid data and blood pressure data, but whose cigarette smoking status is not known.) The ordinate of the graph is the lipid arm and consists of the Cholesterol Retention Fraction (CRF, defined as [LDL-HDL]/LDL). HDL refers to high-density lipoprotein cholesterol and LDL refers to low-density lipoprotein cholesterol. The abscissa of the graph is the blood pressure arm, represented by the systolic blood pressure (SBP). This graph was initially developed in 1981 (using the LDL:HDL ratio) then modified in 1983 (using the CRF), and, by 1988, the author was able to generate a threshold line, which separated the main stream of ATD patients' CRF-SBP plots from those of a few outliers. (The threshold line is not a regression line, but rather a divider, based on the principle of the fewest false negatives.) The 1988 threshold line was modified in 2000 to its present location at CRF-SBP loci $(0.74,100)$ and $(0.49,140)$. [12] Many of the various ATD risk predictors are complex and difficult to use, whereas the graph is simple to use and based on the risk factor constellations of actual ATD patients, wherein lies its value.

The Bowling Green Study (BGS) graph has been presented on numerous occasions [11-15], most recently in 2020, where the original graph was presented and then a version of the graph in which the graph was divided into 48 CRF-SBP cohorts in order to more closely determine the average ages of ATD onset in those patients in each of the CRF-SBP cohorts. While such an approach allows more precise determination of ATD risk for a given patient with a given CRF and a given SBP, when the CRFSBP plots of the 870 patients (or 871 patients if cigarette smoking status is not considered), the numbers of patients within any CRF-SBP cohort 
may vary widely. To compensate for this disadvantage, the author, using the same graph and patients, in this manuscript, presents a three-step method of analyzing ATD risk.

\section{Materials and Methods}

The background of the BGS is been presented on numerous occasion [1315]. In brief, bowling green is a small college town, home of Bowling Green State University. Located in northwest Ohio, bowling green is the county seat of Wood County. The chief employer in bowling green is the University and the city of Bowling Green consists of approximately 28,000 people, about half of whom are college students. The populace is mostly Americans of European descent, with the biggest minority being Americans of Latin American descent. While Americans of African, Asian, and Middle Eastern descent are increasing in numbers, they make up only a small fraction of the population which forms the basis of this publication. The main employer in the area is Bowling Green State University and the hinterland is mainly rural with farming as the chief employment. Many small businesses exist, albeit mainly within the city.

When the author began his practice of family medicine in bowling green in late $1974, \mathrm{He}$ determined to find a way to predict the population at risk of ATD and to do this, he knew that he would need an ATD risk factor database. To this end, he measured blood pressures and heights/weights (converted into body mass index) on each any every patient who presented to his office, each and every time they presented. When the author appreciated the paramount importance of cigarette smoking in ATD, after 1983, he also determined tobacco use status on each patient aged 15 years and older-and after 1993, in all patients aged 10 years or older. The author measured lipid profiles and two hour postprandial blood sugar levels whenever indicated - and any reason to measure such ATD risk factors was considered an adequate reason. Lipid profiles were limited to total cholesterol (CT) and triglycerides (TG) until 1 January 1978, when HDL became available and hence LDL could be calculated by the Friedewald equation [16]. These measurements were collected into a General Population database.

By 1981, the author has accumulated enough ATD patients to begin to separate an ATD database from the General Population database. This happened because, in the 1970's, ATD risk estimates were not very good and in any event were few in number. Additionally, medications used to treat dyslipidemia were not very good and medications to treat hypertension were limited. Finally, in the 1970's and afterwards, patients were not very receptive to the concept of preventive cardiology --and for that matter neither were most of the Wood County physicians.

Inspection of the ATD database revealed that rarely did ATD patients have only one ATD risk factor-usually they were multiple. Hence the author sought to determine which risk factor combinations best predicted ATD risk best. The risk factor combination that was found to be the best predictor was the combination of dyslipidemia and hypertension, and this predictor was only obvious when stratified by cigarette smoking status. Risk factor analysis was straight-forward for SBP and cigarette smoking — but the lipid portion was more complex. Patients with high LDL had ATD events, as expected, but then so did patients with lower LDL levels. People with low levels of HDL had ATD events, but then so did patients with high HDL levels. In 1981 the author saw an article entitled "Is the LDL:HDL Ratio the Best Lipid Predictor?" (The author regrets that the article is now lost to him, so that he cannot give appropriate credit.) With this in mind, the author reexamined his ATD database and discovered that ATD patients with lower LDL levels usually had very low HDL levels and that ATD patients with high HDL levels usually had very high LDL levels. (When this was not the case, the younger patients were cigarette smokers, current of past, while the older patients had hypertension, with or without diabetes.) This finding supported and validated the article's question, and the author began to use the LDL:HDL ratio.

In 1983, it occurred to the author that what he really wanted to know was how much cholesterol was accumulating within the artery walls. This, he reasoned, was best estimated by the difference between the cholesterol entering the artery wall (LDL) and that being removed from the artery wall by reverse cholesterol transport (HDL), expressed as a percentage of the cholesterol entering the artery wall. Thus was born the concept of the CRF. However, it also became obvious to the author that if LDL levels were exceedingly high, then HDL could no longer compensate for LDL. The LDL level at which this occurred was $170 \mathrm{mg} / \mathrm{dl}(4.4 \mathrm{mmoles} / \mathrm{L})$. Thus was born the concept of the cholesterol threshold (C Thr), signifying that dyslipidemia worth treating was present at CRF values of 0.70 or higher or at LDL levels of $170 \mathrm{mg} / \mathrm{dl}(4.4 \mathrm{mmoles} / \mathrm{L})$ or higher. In the BGS, C Thr now forms the basis for defining dyslipidemia.

In the BGS, LDL is not measured, but rather calculated by the Friedewald equation as already noted. The Friedewald equation was developed to estimate LDL levels based of CT, HDL, and TG/5, and HDL is this equation was measured by the precipitation method. (CT means total cholesterol and TG means triglycerides.) In 1999, and without notifying the medical profession, the manufacturers of the auto-analyzers changed from the precipitation method of HDL measurement to the enzymatic method. The two different methodologies give two different values for HDL levels, the enzymatic method giving a value on the order of $10 \mathrm{mg} / \mathrm{d}$ (0.25 mmoles/L) higher than the precipitation method. Hence the calculated LDL value using the enzymatic method will be on the order of $10 \mathrm{mg} / \mathrm{dl}(0.25 \mathrm{mmoles} / \mathrm{L})$ lower than that obtained had the precipitation method been used. While such discrepancies are not highly significant for LDL or HDL, they have a major impact on the CRF. This was reported in 2008. [17] All HDL and OLDL values presented in this paper are based on the precipitation method of HDL-cholesterol measurement. HDLcholesterol measurements (and hence LDL-cholesterol calculations) obtained after the methodology change (in May, 1999) are converted from the enzymatic values to the equivalent precipitation values by the formula given by the Wood County Hospital and is as follows: HDL (precipitation method $)=[\mathrm{HDL}$ (enzymatic method) -12$] / 0.93$. Formulas from other laboratories may differ.

\section{Results}

The BGS graph is shown in Figure I. (If the enzymatic method of HDL measurement is used, the threshold line coordinates are $[0.62,100]$ and $[0.40,140])$. If one then divides the graph into quadrants, using the $\mathrm{SBP}=140$ as the site of the vertical line and $\mathrm{CRF}=0.70$ as the site of the horizontal line, one can then also divide the BGS graph into four quadrants: the left upper quadrant is pure dyslipidemia;, the right upper quadrant is dyslipidemic hypertension; the right lower quadrant is pure hypertension; and the left lower quadrant is neither. (See Figure II.) Treated hypertensives have their plots shifted to the adjacent zone on the right, whereas patients with $\mathrm{C}$ Thr are shifted to the adjacent zone superiorly. Dyslipidemic patients treated pharmacologically are not included, but are few in number. Table I shows the ATD outcomes of the patients until the end of 2003 because at the end of 2003, there was a major shift in insurance coverage when a new start-up insurance company entered the Wood County area and the author lost a sizeable portion of his practice, including many ATD patients, to the new insurance plan. Prior to this event, the author had basically full knowledge of his ATD patients' outcomes, but not thereafter. 


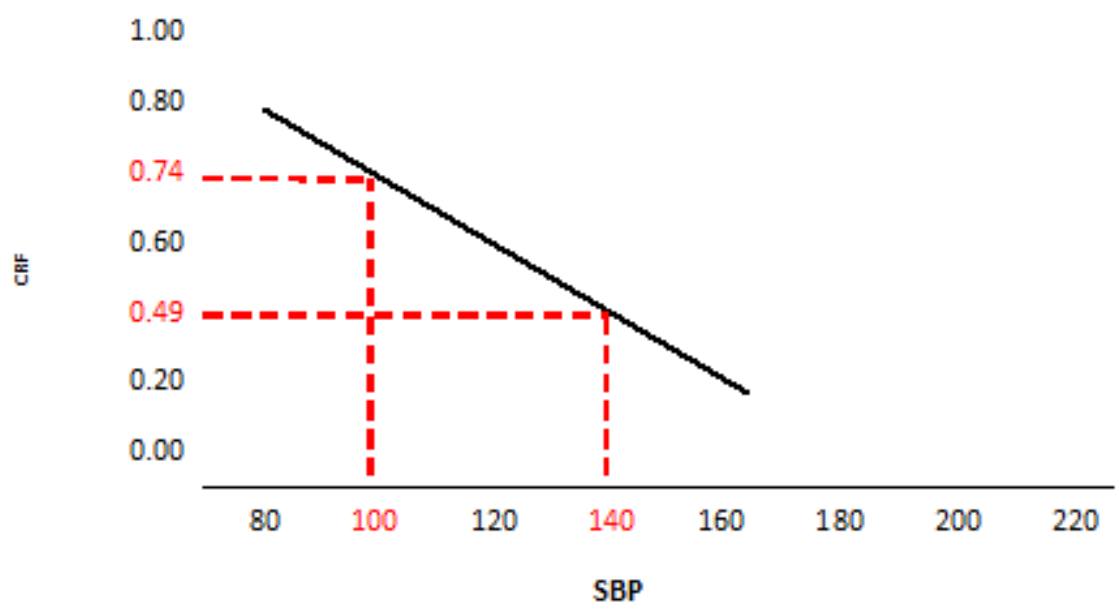

CRF means Cholesterol Retention Fraction

SBP Means Systolic Blood Pressure

HDL means High Density Lipoprotein

Figure I

\begin{tabular}{|c|c|c|c|c|c|c|c|c|}
\hline Sex & Average Age of & & + & Past & - & + & Past & - \\
\hline \multicolumn{9}{|l|}{ Male } \\
\hline & & Total Patients & 126 & 130 & 86 & 20 & 14 & 8 \\
\hline & ATD Onset & Total Patient Years & 6659 & 8536 & 5913 & 1174 & 1041 & 623 \\
\hline & & Ave. Age of ATD Onset & 53 & 66 & 69 & 59 & 74 & 78 \\
\hline & & Total Patients & 38 & 41 & 32 & 6 & 5 & 1 \\
\hline & MSD Onset & Total Patient Years & 2363 & 2983 & 2522 & 382 & 402 & 78 \\
\hline & & Ave Age of MSD Onset & 62 & 73 & 79 & 64 & 80 & 78 \\
\hline & & & & & & & & \\
\hline & & Total Patients & 49 & 64 & 47 & 12 & 11 & 4 \\
\hline & Death & Total Patient Years & 3153 & 4780 & 3805 & 815 & 879 & 374 \\
\hline & & Ave Age of Death & 64 & 75 & 81 & 68 & 80 & 94 \\
\hline \multicolumn{9}{|l|}{ Female } \\
\hline & & Total Patients & 65 & 56 & 137 & 18 & 15 & 34 \\
\hline & ATD Onset & Total Patient Years & 3852 & 3908 & 9955 & 1145 & 1003 & 2543 \\
\hline & & Ave. Age of ATD Onset & 59 & 70 & 73 & 64 & 67 & 75 \\
\hline & & & & & & & & \\
\hline
\end{tabular}




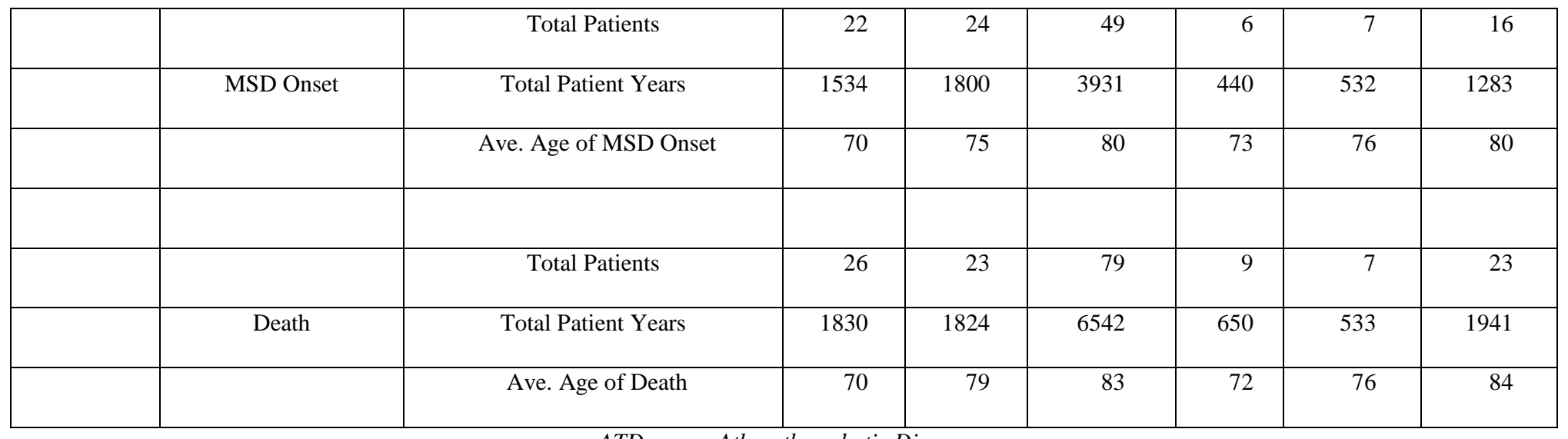

ATD means Atherothrombotic Disease

"+” means Current Cigarette Smoker

"Past” means Former Cigarette Smoker

“- “ means Never Cigarette Smoker

MSD means Multiple System Disorder

ASR Line means Angiographic Stabilization/Regression Line

Table I: ATD w/r to ASR Line 1974-2003

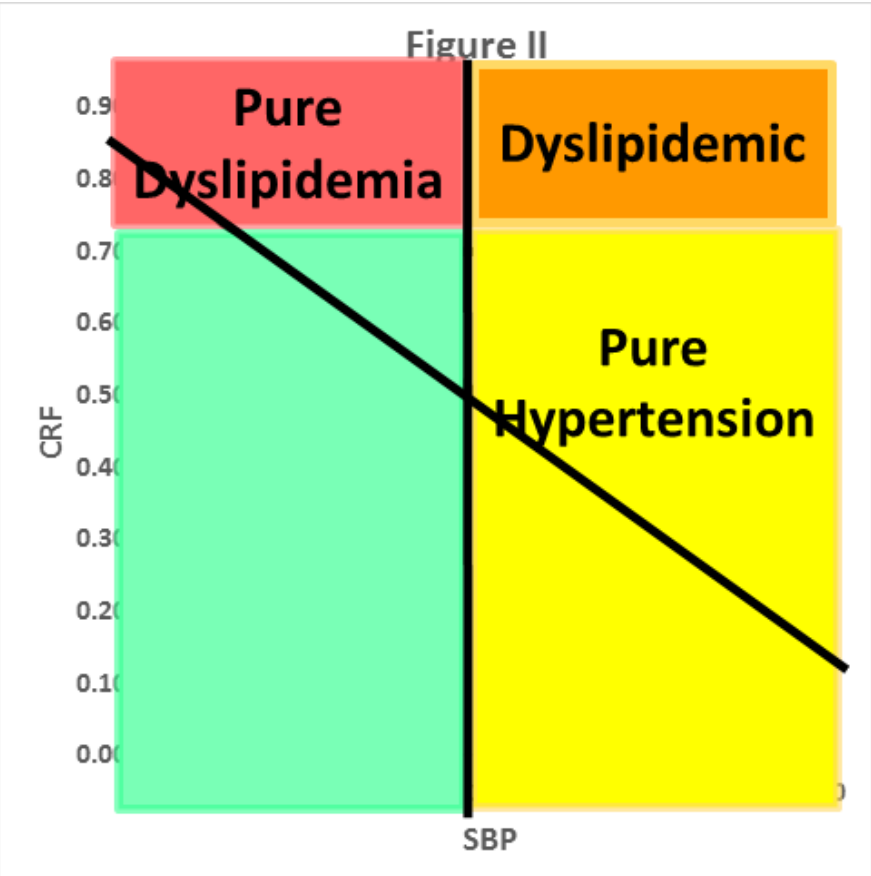

Once the quadrant divisions are in place, the various subdivisions can be named. The left upper quadrant is termed Zone I, with patients above the threshold line receiving the designation " $\mathrm{A}$ " and patients below the threshold line receiving the designation "B." The right upper quadrant is termed Zone II, and all plots are above the threshold line. The right lower quadrant is termed Zone III, with the subdivisions of " $\mathrm{A}$ " being above the threshold line and " $\mathrm{B}$ " being below the threshold line. The left lower quadrant is termed Zone IV, with subdivisions of "A" being above the threshold line and "B" being below the threshold line. (See Figure III.)Each of these subdivisions can be stratified by cigarette smoking status. (See See Figure IV-A for males and IV-B for females, and Tables II-A for males and II-B for females. Each subdivision demonstrates the average age of the patients in that subdivision.) 


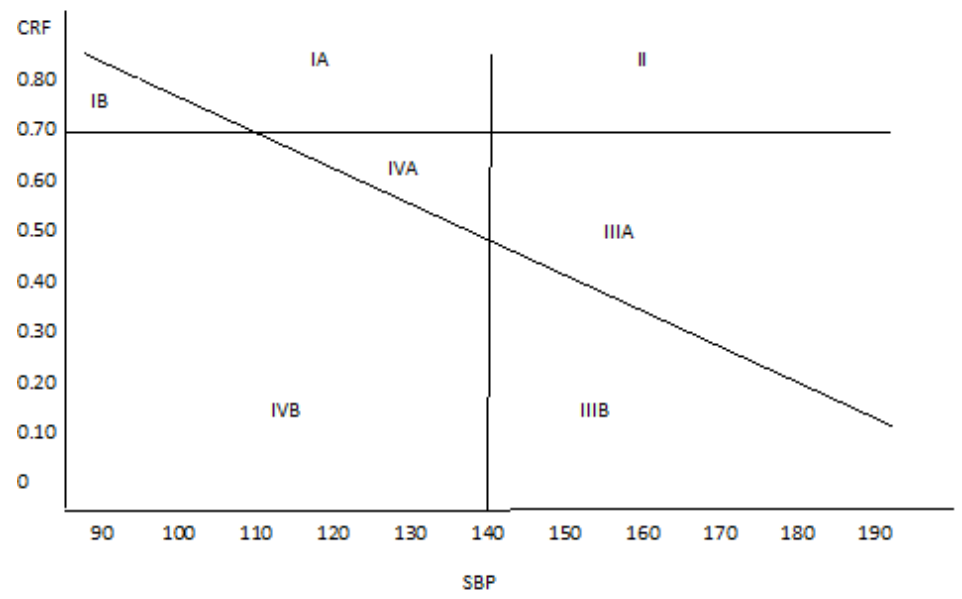

BGS Means Bowling Green Study

ATD Means Atherothrombotic Disease

CRF Means Cholesterol Retention Fraction

SBP Means Systolic Blood Pressure

Figure III: BGS Graph Angles and Triangles

\begin{tabular}{|c|c|c|c|c|c|c|}
\hline Zone & & + & Past & $\sum-$ & $?$ & $\sum$ \\
\hline \multicolumn{7}{|l|}{ IA } \\
\hline & ATD Pop & $\begin{array}{c}61 \\
480 \\
13 \% \\
\end{array}$ & $\begin{array}{c}41 \\
480 \\
9 \% \\
\end{array}$ & $\begin{array}{c}39 \\
480 \\
8 \% \\
\end{array}$ & & $\begin{array}{r}141 \\
480 \\
29 \% \\
\end{array}$ \\
\hline \multicolumn{7}{|l|}{ IA } \\
\hline & Gen Pop & $\begin{array}{c}190 \\
1635 \\
12 \%\end{array}$ & $\begin{array}{c}100 \\
1635 \\
6 \%\end{array}$ & $\begin{array}{c}201 \\
1635 \\
12 \%\end{array}$ & $\begin{array}{c}13 \\
1635 \\
1 \%\end{array}$ & $\begin{array}{c}504 \\
1635 \\
21 \%\end{array}$ \\
\hline \multicolumn{7}{|l|}{ IB } \\
\hline & ATD Pop & $\begin{array}{c}2 \\
480 \\
\sim 0 \% \\
\end{array}$ & & $\begin{array}{c}2 \\
480 \\
\sim 0 \%\end{array}$ & & $\begin{array}{c}4 \\
480 \\
1 \% \\
\end{array}$ \\
\hline \multicolumn{7}{|l|}{ IB } \\
\hline & Gen Pop & $\begin{array}{c}4 \\
1635 \\
\sim 0 \% \\
\end{array}$ & $\begin{array}{c}3 \\
1635 \\
\sim 0 \%\end{array}$ & $\begin{array}{c}7 \\
1635 \\
\sim 0 \% \\
\end{array}$ & $\begin{array}{c}1 \\
1635 \\
\sim 0 \%\end{array}$ & $\begin{array}{c}15 \\
1635 \\
1 \%\end{array}$ \\
\hline \multicolumn{7}{|l|}{ II } \\
\hline & ATD Pop & $\begin{array}{c}56 \\
480 \\
12 \%\end{array}$ & $\begin{array}{c}64 \\
480 \\
13 \%\end{array}$ & $\begin{array}{c}41 \\
480 \\
9 \%\end{array}$ & & $\begin{array}{c}161 \\
480 \\
34 \%\end{array}$ \\
\hline \multicolumn{7}{|l|}{ II } \\
\hline & Gen Pop & $\begin{array}{c}94 \\
1635 \\
6 \% \\
\end{array}$ & $\begin{array}{c}80 \\
1635 \\
5 \% \\
\end{array}$ & $\begin{array}{c}106 \\
1635 \\
6 \% \\
\end{array}$ & $\begin{array}{c}10 \\
1635 \\
1 \% \\
\end{array}$ & $\begin{array}{c}290 \\
1635 \\
18 \% \\
\end{array}$ \\
\hline \multicolumn{7}{|l|}{ IIIA } \\
\hline & ATD Pop & $\begin{array}{c}24 \\
480 \\
5 \%\end{array}$ & $\begin{array}{c}30 \\
480 \\
6 \%\end{array}$ & $\begin{array}{c}21 \\
480 \\
4 \%\end{array}$ & & $\begin{array}{c}75 \\
480 \\
16 \%\end{array}$ \\
\hline \multicolumn{7}{|l|}{ IIIA } \\
\hline & Gen Pop & $\begin{array}{c}59 \\
1635\end{array}$ & $\begin{array}{c}49 \\
1635\end{array}$ & $\begin{array}{c}45 \\
1635\end{array}$ & $\begin{array}{c}15 \\
1635\end{array}$ & $\begin{array}{c}168 \\
1635\end{array}$ \\
\hline
\end{tabular}




\begin{tabular}{|c|c|c|c|c|c|c|}
\hline & & $4 \%$ & $3 \%$ & $3 \%$ & $1 \%$ & $10 \%$ \\
\hline Zone & & + & Past & $\sum-$ & $?$ & $\sum$ \\
\hline \multicolumn{7}{|l|}{ IIIB } \\
\hline & ATD Pop & $\begin{array}{c}4 \\
480 \\
1 \%\end{array}$ & $\begin{array}{c}12 \\
480 \\
2 \%\end{array}$ & $\begin{array}{c}3 \\
480 \\
1 \%\end{array}$ & & $\begin{array}{c}19 \\
480 \\
4 \%\end{array}$ \\
\hline \multicolumn{7}{|l|}{ IIIB } \\
\hline & Gen Pop & $\begin{array}{c}12 \\
1635 \\
1 \% \\
\end{array}$ & $\begin{array}{c}13 \\
1635 \\
1 \% \\
\end{array}$ & $\begin{array}{c}5 \\
1635 \\
\sim 0 \% \\
\end{array}$ & $\begin{array}{c}1 \\
1635 \\
\sim 0 \% \\
\end{array}$ & $\begin{array}{c}31 \\
1635 \\
2 \%\end{array}$ \\
\hline \multicolumn{7}{|l|}{ IVA } \\
\hline \multicolumn{7}{|l|}{ IVA } \\
\hline & Gen Pop & $\begin{array}{c}73 \\
1635 \\
4 \% \\
\end{array}$ & $\begin{array}{c}57 \\
1635 \\
3 \% \\
\end{array}$ & $\begin{array}{c}87 \\
1635 \\
5 \% \\
\end{array}$ & $\begin{array}{c}10 \\
1635 \\
1 \% \\
\end{array}$ & $\begin{array}{c}227 \\
1635 \\
14 \% \\
\end{array}$ \\
\hline \multicolumn{7}{|l|}{ IVB } \\
\hline & ATD Pop & $\begin{array}{c}20 \\
480 \\
4 \% \\
\end{array}$ & $\begin{array}{c}11 \\
480 \\
2 \%\end{array}$ & $\begin{array}{c}8 \\
480 \\
2 \% \\
\end{array}$ & $\begin{array}{c}1 \\
480 \\
\sim 0 \%\end{array}$ & $\begin{array}{c}40 \\
480 \\
8 \%\end{array}$ \\
\hline \multicolumn{7}{|l|}{ IVB } \\
\hline & Gen Pop & $\begin{array}{c}97 \\
1635 \\
6 \%\end{array}$ & $\begin{array}{c}42 \\
1635 \\
3 \%\end{array}$ & $\begin{array}{c}204 \\
1635 \\
12 \%\end{array}$ & $\begin{array}{c}57 \\
1635 \\
3 \%\end{array}$ & $\begin{array}{c}400 \\
1635 \\
24 \%\end{array}$ \\
\hline
\end{tabular}

ATD Means Atherothrombotic Disease

+ Means Current Cigarette Smoker

Past Means Past Cigarette Smoker

- Means No History of Smoking Cigarettes

? Means Unknown Smoking History

Table IIA: Zonal Incidence in Male ATD Population Vs Male General population \% of Whole Cigarettes

\begin{tabular}{|c|c|c|c|c|c|c|}
\hline Zone & & + & Past & $\sum-$ & ? & $\sum$ \\
\hline \multicolumn{7}{|l|}{ IA } \\
\hline & ATD Pop & $\begin{array}{c}36 \\
391 \\
9 \%\end{array}$ & $\begin{array}{c}15 \\
391 \\
4 \%\end{array}$ & $\begin{array}{c}27 \\
391 \\
7 \% \\
\end{array}$ & & $\begin{array}{c}78 \\
391 \\
20 \%\end{array}$ \\
\hline \multicolumn{7}{|l|}{ IA } \\
\hline & Gen Pop & $\begin{array}{c}125 \\
1628 \\
8 \%\end{array}$ & $\begin{array}{c}57 \\
1628 \\
4 \%\end{array}$ & $\begin{array}{c}121 \\
1628 \\
7 \%\end{array}$ & $\begin{array}{c}13 \\
1628 \\
1 \%\end{array}$ & $\begin{array}{c}316 \\
1628 \\
19 \%\end{array}$ \\
\hline \multicolumn{7}{|l|}{ IB } \\
\hline & ATD Pop & $\begin{array}{c}1 \\
391 \\
\sim 0 \%\end{array}$ & $\begin{array}{c}1 \\
391 \\
\sim 0 \%\end{array}$ & $\begin{array}{c}1 \\
391 \\
\sim 0 \%\end{array}$ & & $\begin{array}{c}3 \\
391 \\
1 \%\end{array}$ \\
\hline \multicolumn{7}{|l|}{ IB } \\
\hline & Gen Pop & $\begin{array}{c}11 \\
1628 \\
1 \% \\
\end{array}$ & $\begin{array}{c}2 \\
71628 \\
\sim 0 \% \\
\end{array}$ & $\begin{array}{c}16 \\
1628 \\
1 \% \\
\end{array}$ & $\begin{array}{c}1 \\
1628 \\
\sim 0 \% \\
\end{array}$ & $\begin{array}{c}30 \\
1628 \\
2 \% \\
\end{array}$ \\
\hline \multicolumn{7}{|l|}{ II } \\
\hline & ATD Pop & $\begin{array}{c}25 \\
391 \\
6 \%\end{array}$ & $\begin{array}{c}25 \\
391 \\
6 \%\end{array}$ & $\begin{array}{c}67 \\
391 \\
17 \%\end{array}$ & & $\begin{array}{c}117 \\
391 \\
30 \%\end{array}$ \\
\hline
\end{tabular}




\begin{tabular}{|c|c|c|c|c|c|c|}
\hline II & & & & & & \\
\hline & Gen Pop & $\begin{array}{c}51 \\
1628 \\
3 \% \\
\end{array}$ & $\begin{array}{c}37 \\
1628 \\
2 \% \\
\end{array}$ & $\begin{array}{c}76 \\
1628 \\
5 \% \\
\end{array}$ & $\begin{array}{c}6 \\
1628 \\
\sim 0 \% \\
\end{array}$ & $\begin{array}{c}170 \\
1628 \\
10 \% \\
\end{array}$ \\
\hline \multicolumn{7}{|l|}{ IIIA } \\
\hline & ATD Pop & $\begin{array}{c}14 \\
391 \\
4 \% \\
\end{array}$ & $\begin{array}{c}19 \\
391 \\
5 \% \\
\end{array}$ & $\begin{array}{c}49 \\
391 \\
13 \% \\
\end{array}$ & & $\begin{array}{c}82 \\
391 \\
21 \% \\
\end{array}$ \\
\hline \multicolumn{7}{|l|}{ IIIA } \\
\hline & Gen Pop & $\begin{array}{c}21 \\
1628 \\
1 \% \\
\end{array}$ & $\begin{array}{c}18 \\
1628 \\
1 \% \\
\end{array}$ & $\begin{array}{c}68 \\
1628 \\
4 \% \\
\end{array}$ & $\begin{array}{c}16 \\
1628 \\
1 \% \\
\end{array}$ & $\begin{array}{c}123 \\
1628 \\
8 \% \\
\end{array}$ \\
\hline
\end{tabular}

\begin{tabular}{|c|c|c|c|c|c|c|}
\hline Zone & & + & Past & $\sum-$ & $?$ & $\sum$ \\
\hline \multicolumn{7}{|l|}{ IIIB } \\
\hline & & 6 & 5 & 15 & & 26 \\
\hline & ATD Pop & 391 & 391 & 391 & & 391 \\
\hline & & $2 \%$ & $1 \%$ & $4 \%$ & & $7 \%$ \\
\hline \multicolumn{7}{|l|}{ IIIB } \\
\hline & & 14 & 10 & 35 & 1 & 60 \\
\hline & Gen Pop & 1628 & 1628 & 1628 & 1628 & 1628 \\
\hline & & $1 \%$ & $2 \%$ & $2 \%$ & $\sim 0 \%$ & $4 \%$ \\
\hline & & & & & & \\
\hline & & & & & & \\
\hline \multicolumn{7}{|l|}{ IVA } \\
\hline & & 11 & 3 & 12 & & 26 \\
\hline & ATD Pop & 391 & 391 & 391 & & 391 \\
\hline & & $3 \%$ & $1 \%$ & $3 \%$ & & $7 \%$ \\
\hline \multicolumn{7}{|l|}{ IVA } \\
\hline & & 58 & 31 & 78 & 14 & 181 \\
\hline & Gen Pop & 1628 & 1628 & 1628 & 1628 & 1628 \\
\hline & & $3 \%$ & $2 \%$ & $5 \%$ & $1 \%$ & $11 \%$ \\
\hline & & & & & & \\
\hline & & & & & & \\
\hline \multicolumn{7}{|l|}{ IVB } \\
\hline & & 17 & 12 & 30 & & 59 \\
\hline & ATD Pop & 391 & 391 & 391 & & 391 \\
\hline & & $4 \%$ & $3 \%$ & $8 \%$ & & $15 \%$ \\
\hline \multicolumn{7}{|l|}{ IVB } \\
\hline & & 160 & 66 & 385 & 137 & 748 \\
\hline & Gen Pop & 1628 & 1628 & 1628 & 1628 & 1628 \\
\hline & & $10 \%$ & $4 \%$ & $24 \%$ & $8 \%$ & $46 \%$ \\
\hline
\end{tabular}

ATD Means Atherothrombotic Disease

+ Means Current Cigarette Smoker

Past Means Past Cigarette Smoker

- Means No History of Smoking Cigarettes

? Means Unknown Smoking History 


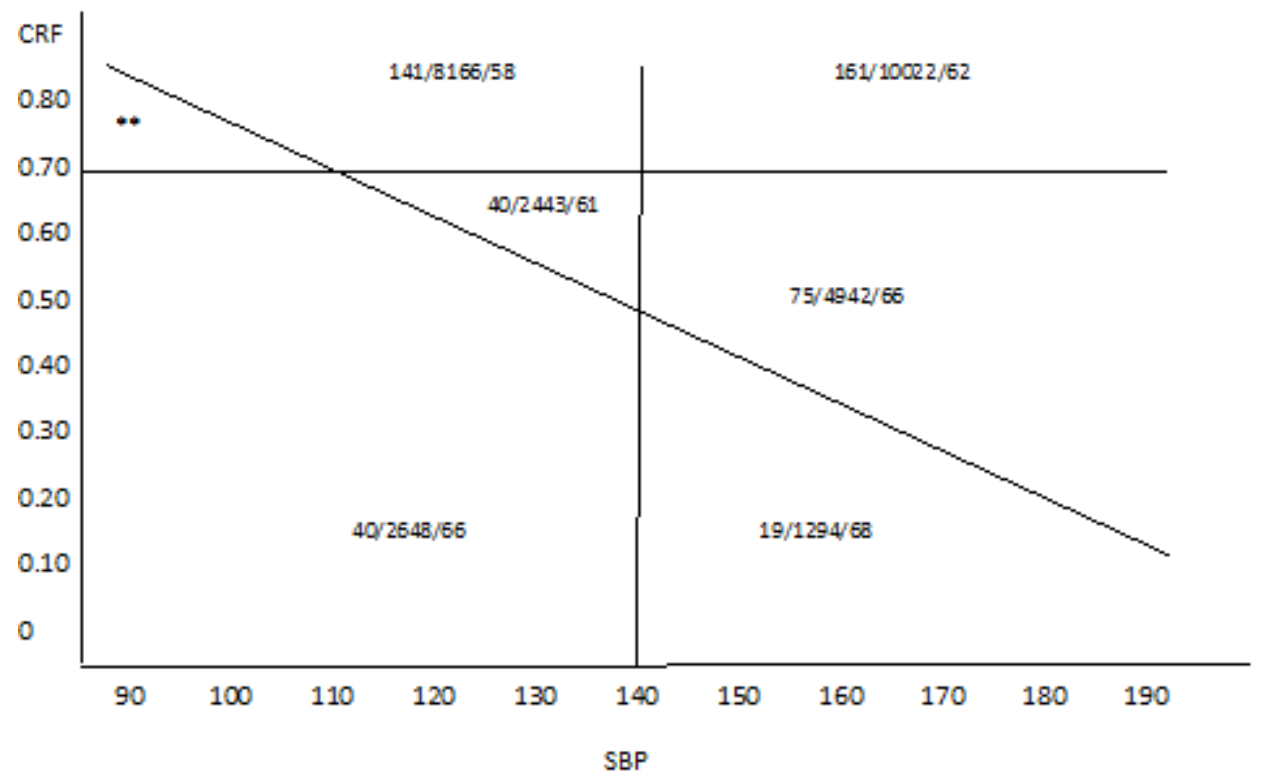

BGS Means Bowling Green Study

ATD Means Atherothrombotic Disease

CRF Means Cholesterol Retention Fraction

SBP Means Systolic Blood Pressure

$* * 4 / 256 / 64$

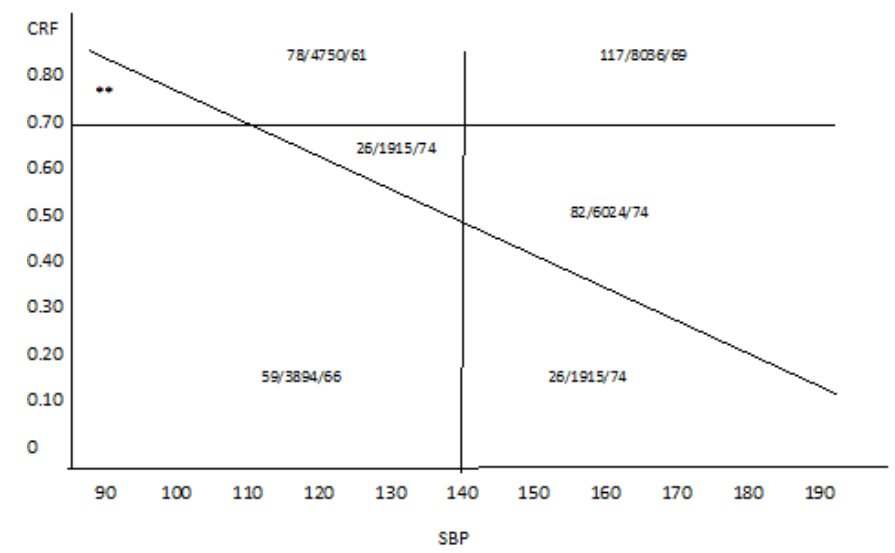

BGS Means bowling green Study

ATD Means Atherothrombotic Disease

CRF Means Cholesterol Retention Fraction

SBP Means Systolic Blood Pressure

$* * 3 / 174 / 58$

Figure IVB: Average Age of ATD Onset Female ATD Population

In the BGS ATD database, the quadrant with the most patients in both men and women is Zone II; however, the Zone with the youngest such patients is Zone I. The subdivision with the youngest patients is Zone IA,
Zone IB being excluded due to very small numbers. The youngest patients in Zone IA are the cigarette smokers, followed by ex-smokers, and then by never-smokers, and this is true for all Zones. Interestingly, 
the patients in Zone I tend to be younger than those in Zone II, who in turn tend to younger than those in Zone III. This demonstrates the greater importance of dyslipidemia and the lesser importance of hypertension in clinical ATD. On the other hand the incidence of cigarette smoking is greatest in Zone I patients and falls off progressively in Zones II and III.

The patients in Zone IV have neither dyslipidemia (as the author has defined it) nor hypertension. In men, the highest incidence of cigarette smoking is seen in Zone IV, whereas in women, the Zone IV incidence in cigarette smoking is second only to that in Zone I. Some of the women in Zone IV had had central chest radiation for lymphomas and others were taking cyclic-sequential hormone replacement therapy (HRT), which may favorably influence lipid levels or continuous-combined HRT, which is known to promote thrombosis in susceptible women. Other women had hypercoagulable states. And finally, many never-smoking women suffered from passive cigarette smoking courtesy of their husbands. All of these conditions adversely affect the age on ATD onset. While any of these conditions may affect the age of ATD onset, the overwhelming risk factor is cigarette smoking since only $38 \%(15 / 40)$ of males were never cigarette smokers and only $49 \%(42 / 85)$ of females were never cigarette smokers.

The BGS graph can also be divided into 48 CRF-SBP cohorts, as shown in Figures $\mathrm{V}$ A-D. This permits a more precise determination in average age of ATD onset, though at the expense of fewer patients per cohort.

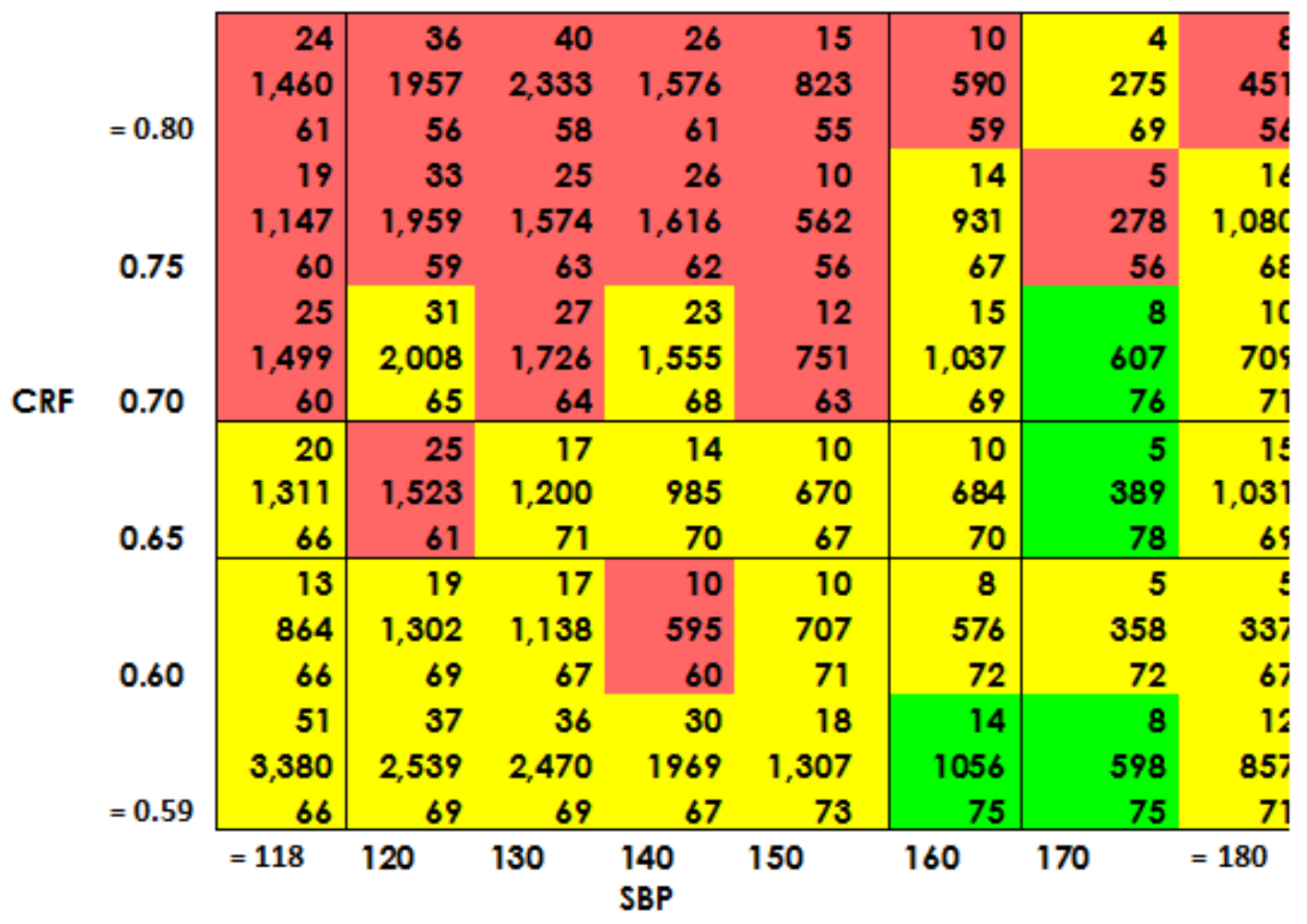

CRF vs SBP: Original Logs

$\Sigma$ Male \& Female: $\Sigma$ Cigarettes

BGS ATD pop : $\Sigma$

CRF means Cholesterol Retention Fraction

SBP means Systolic Blood Pressure

BGS means Bowling Green Study

ATD means Atherothrombotic Disease 


\begin{tabular}{|c|c|c|c|c|c|c|c|c|}
\hline \multirow[b]{3}{*}{$=0.80$} & 9 & 18 & 17 & 12 & 7 & 4 & & 3 \\
\hline & 441 & 817 & 885 & 632 & 339 & 228 & & 145 \\
\hline & 49 & 45 & 52 & 53 & 48 & 57 & & 48 \\
\hline & 7 & 11 & 11 & 8 & 3 & 5 & 1 & 4 \\
\hline & 369 & 681 & 587 & 431 & 161 & 297 & 45 & 233 \\
\hline \multirow[t]{3}{*}{0.75} & 53 & 62 & 53 & 54 & 54 & 59 & 45 & 58 \\
\hline & 11 & 9 & 11 & 5 & 2 & 3 & 3 & 1 \\
\hline & 620 & 455 & 600 & 311 & 91 & 155 & 215 & 56 \\
\hline \multirow[t]{3}{*}{ CRF } & 56 & 51 & 55 & 62 & 46 & 52 & 72 & 56 \\
\hline & 8 & 9 & 2 & 2 & 3 & 3 & & 5 \\
\hline & 441 & 431 & 151 & 130 & 138 & 169 & & 244 \\
\hline \multirow[t]{3}{*}{0.65} & 55 & 48 & 76 & 65 & 46 & 56 & & 49 \\
\hline & 8 & 10 & 7 & 4 & 2 & 2 & 1 & 1 \\
\hline & 418 & 628 & 448 & 222 & 128 & 117 & 50 & 76 \\
\hline \multirow[t]{3}{*}{0.60} & 52 & 63 & 64 & 56 & 64 & 59 & 50 & 76 \\
\hline & 20 & 10 & 6 & 13 & 3 & 3 & 3 & 4 \\
\hline & 1,212 & 569 & 369 & 703 & 201 & 183 & 184 & 236 \\
\hline \multirow[t]{3}{*}{$=0.59$} & 61 & 57 & 62 & 54 & 67 & 61 & 61 & 59 \\
\hline & $=118$ & 120 & 130 & 140 & 150 & 160 & 170 & $=180$ \\
\hline & & & & SBP & & & & \\
\hline
\end{tabular}

CRF means Cholesterol Retention Fraction

SBP means Systolic Blood Pressure

BGS means Bowling Green Study

ATD means Atherothrombotic Disease

Figure V B- means no history of cigarette smoking

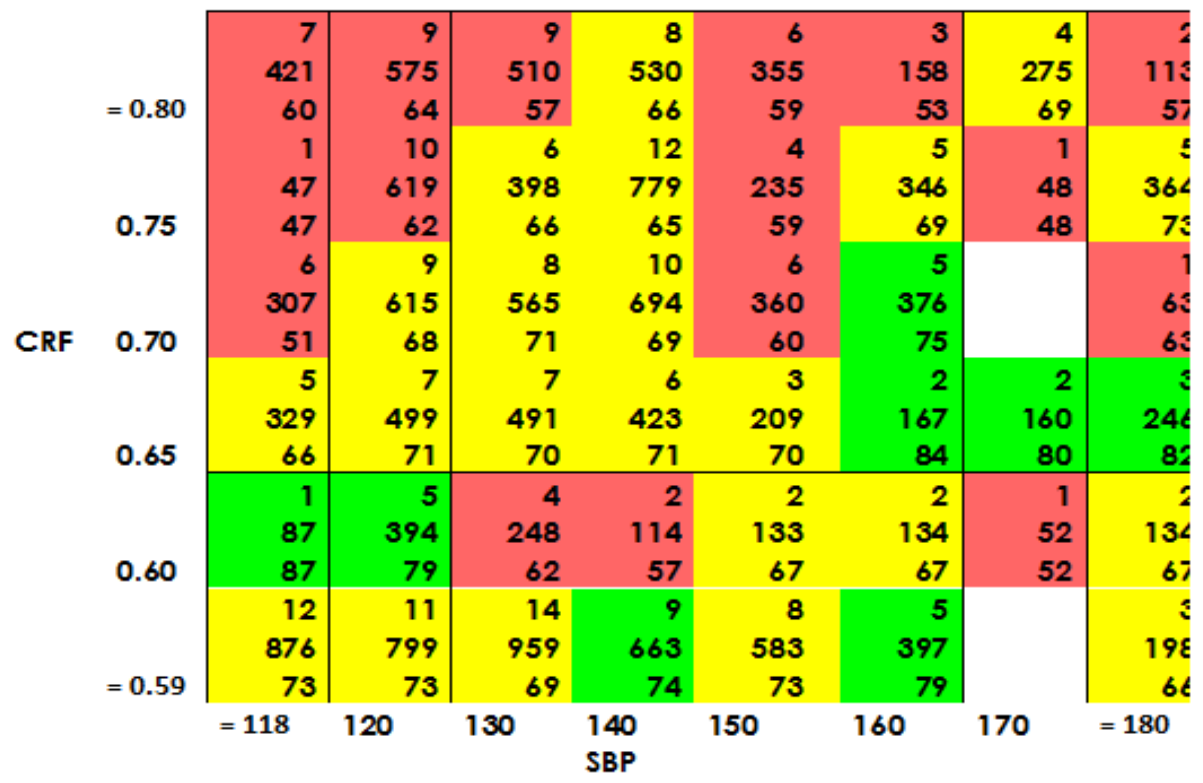

CRF means Cholesterol Retention Fraction

SBP means Systolic Blood Pressure

BGS means Bowling Green Study

ATD means Atherothrombotic Disease 


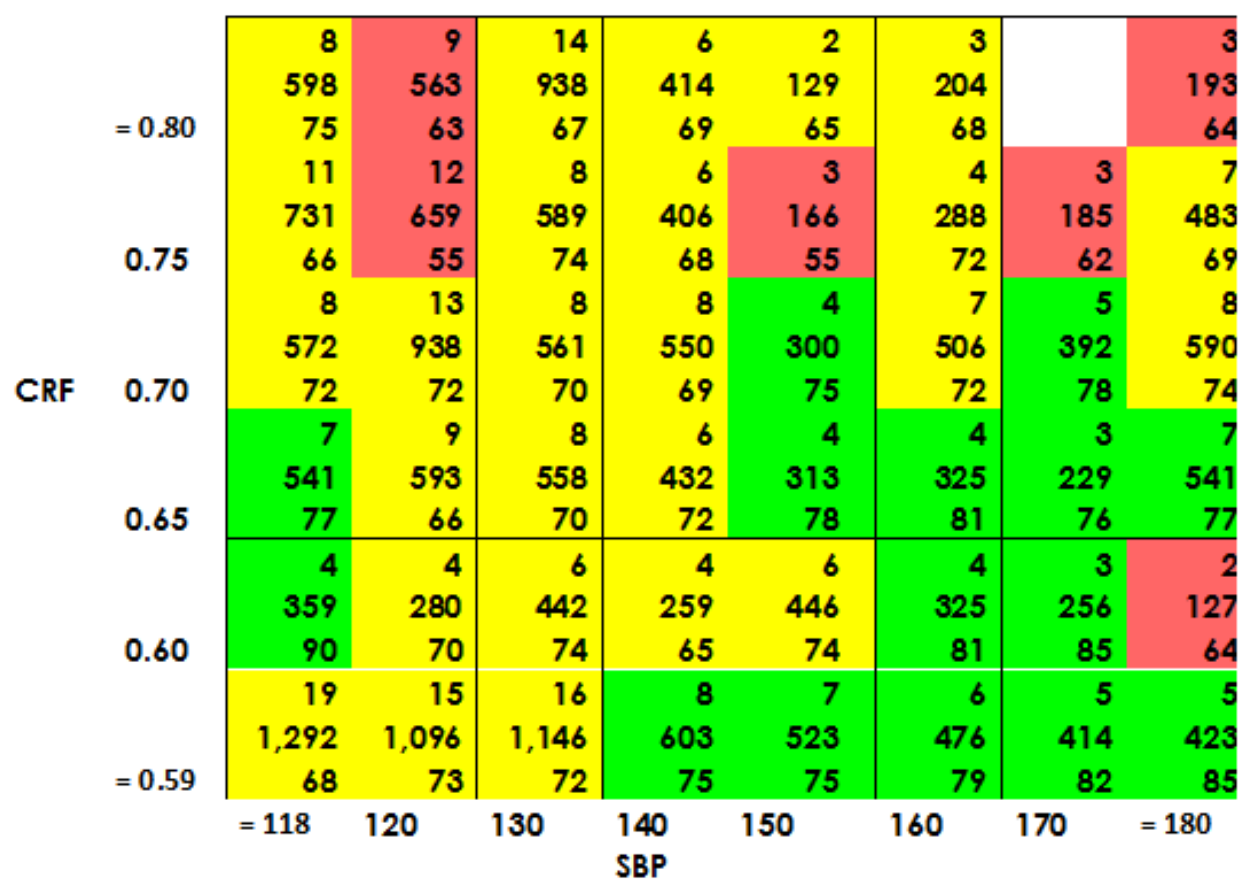

CRF means Cholesterol Retention Fraction

SBP means Systolic Blood Pressure

BGS means Bowling Green Study

ATD means Atherothrombotic Disease

Figure V D- means no history of cigarette smoking

The same graphic technique can be applied to the BGS general population base. The data comparing the BGS ATD population and the BGS general population base is displayed in Tables II-A for males and II-B for females. It will be noted that a CRF-SBP plot in Zones II and III favors the ATD population whereas a CRF-SBP plot in Zone IV favors the general population.

\section{Discussion}

The prediction of the population at risk of ATD requires knowledge of those persons' ATD risk factors. The better that a physician can predict the population at risk of ATD, the better, at least in theory, he/she can prevent clinical ATD events. Since ATD risk factors rarely act in isolation, it is essential that the risk predictor tool utilize an integration of the individual ATD risk factors, rather than treating them as independent factors. Moreover, as William E. Connor, MD, noted in the mid 1970's, physicians should not treat various risk factors to an arbitrary goal, but rather to levels that prevent disease. (Medical World News, mid 1970's, exact source lost to the author) This graph fulfills all of these criteria.

The chief ATD risk factors are cigarette smoking, dyslipidemia, and hypertension, with some contribution by the very high blood sugar levels of uncontrolled diabetes. (18) However, the author has shown that the various ATD risk factors rarely operate independently and therefore any predictive tool must treat the various risk factors as dependent variables. To this end, the author has presented a unique method of estimating that risk-i.e., the BGS graph. This graph has been presented as a graph with no subdivisions - simply a determination as to whether the CRF-SBP plot is below or above the threshold line. This graph can in turn be divided into quadrants, defining dyslipidemia and hypertension or lack thereof. This approach has the advantage of being more specific as to degree of risk, but the numbers in each cohort will be somewhat smaller. The graph can then be divided into 48 CRF-SBP cohorts, but while this permits more precise definition of ATD risk, the numbers in each CRF-SBP cohort will of necessity be much fewer.

The author suggests a three-step approach. First, obtain the patient's CRF (or C Thr as applicable), SBP, and cigarette smoking status. Then plot the data on the simple BGS graph. If the patient's plot position is below the threshold line and he/she does not have $\mathrm{C}$ Thr and if the patient has never smoked cigarettes, then nothing need be done since the patient is of little risk of ATD; however, periodic follow up must be done to assure that the patient remains at very low risk. If the patient is an exsmoker, again nothing need be done, though periodic follow-up is needed to assure that the patient remains within the low risk zone. If the patient is a cigarette smoker, he/she must give up the smoking habit, and of course be followed periodically.

If, on the other hand, the CRF-SBP plot lies above the threshold line (first order approximation of ATD risk), then the next step is the determination of which quadrant the CRF-SBP plot lies within and where the CRF-SBP plot lies with respect to the threshold line. Figures III-A (males) and IIIB (females) give a second order approximation of ATD risk. As noted previously, subdividing the BGS graph into its 48 CRF-SBP cohorts, will then give highest (third order) approximation of ATD risk, though the numbers of patients per cohort will be fewer. The third order approximation of ATD risk should be definitive; however, if one lives long enough and does not die of something else, an ATD event is likely to occur sometime due to the ravages of time upon the human body. There is no zone of "zero" ATD risk, only areas of low ATD risk. While low risk zones imply a lack of ATD onset at early or middle ages, it does not imply a lack of ATD events in very old age.

The figures for the third order approximation are shown in Figures V AD. Since there are 48 possible CRF-SBP combinations and there are only 871 ATD patients, males and females are grouped together. Figure V-A gives the averages of ATD onset per CRF-SBP cohort without regard for 
cigarette smoking status and thus includes the 75 year old man whose cigarette smoking status is not known. Figure V-B gives the same data for patients currently smoking cigarettes at time of ATD onset; Figure VC, for ex-smokers; and Figure V-D, for never smokers, though other forms of tobacco use were allowed, such as pipe or cigar smoking or tobacco chewing, provided that the patient never smoked cigarettes. Cohorts in which the average age of ATD onset is 64 years or younger are color-coded red; cohorts with an average age of ATD onset of 65-74 years, color-coded yellow; and cohorts with an average age of ATD onset of 75 years or older, color-coded green. The patient need only go to the appropriate CRF-SBP cohort to see his/her risk and then determine the need of urgency of treatment. It will be noted that clear-cut zones of risk can be seen in Figures V C-D, but not for Figure V-B. This is discussed more fully in reference 11 .

The success of the above regimen depends upon the early detection of the ATD risk factors. If the risk factors are undetected or untreated long enough, then even if the risk factors are eventually corrected, even optimally, an early ATD event may occur. The reason for this is that the plaque has a central lipid core, covered over by a fibrous cap. It is possible to shrink the cholesterol core, but it is not possible, with today's medications, to shrink the fibrous plaque. The fibrous cap creates a disturbance in the laminar flow of blood, which signals the body's homeostatic mechanism to lay down more fibrous tissue, which eventually compromises blood flow and may precipitate a thrombus, giving rise to an acute ATD event.

The success of this regimen is also dependent upon achieving risk factor control that minimizes plaque progression and maximizes plaque stabilization/regression. This requires achieving an LDL goal of $80 \mathrm{mg} / \mathrm{dl}$ $(2.0$ mmoles/L) if the precipitation method of measuring HDL is used or $70 \mathrm{mg} / \mathrm{dl}$ (1.75 mmoles/L) if the enzymatic method is utilized [19-20]. Cigarette smoking must be given up. SBP must be controlled to a minimum of $140 \mathrm{~mm} \mathrm{Hg}$. Of course the blood sugar levels of diabetes must be controlled as well.

\section{Conclusions}

The BGS graph for the prediction of the population at risk of ATD can be presented in the three steps as noted above. The first approach utilizes the graph with respect to the threshold line. The second divides the graph into zones, which gives increasing accuracy of prediction per cohort but which sacrifices strength of numbers. What the third step loses in numbers of patients per subdivision, it makes up for by increased accuracy of prediction. The ease of this approach makes it valuable for general physicians and patients alike to understand and to use it.

\section{References}

1. Kannel WB, McGee D, Gordon T (1976). A General Cardiovascular Risk Profile: The Framingham Study. Am J Cardiol.38 (1)"46-51

2. Wallis EJ, Ramsey LE, Ul Haq I, Ghahramani P, Jackson PR, Rowland-Yeo K, Yeo WW (2000). Coronary and Cardiovascular Risk Estimation for Primary Prevention: Validation of a New Sheffield Table in the 1995 Scottish Health Survey Population. BMJ; 320:671-676

3. D'Augostino RB Sr, GrundyS, Sullivan LM, Wilson P (2001) .CHD Risk Prediction Group. Validation of the Framingham Coronary Heart Disease Prediction Scorres: Results of a Multiple Ethnic Group Investigation. JAMA. 286(2):180-187.
4. Berry JD, Dyer A, Cai X. et al (2012). Lifetime Risks of Cardiovascular Disease. N Eng J Med. 366 (4): 321-329.

5. Lloyd-Jones DM, Wilson PWF, Larson MG, Beiser A, Leip EP, D'agnstino RB, Levy D (2004). Framingham Risk Scoreand Prediction of Lifetime Risk for Coronary Heart Disease. Am J Cardiol.94: 20-24.

6. Mortensen MB, Nordestgaard BG (2020). 2019 vs 2016 ESC/EAS Statin Guidelines for Primary Prevention of Atherosclerotic Cardiovascular Disease. European Heart Journal. 41 (31): 3005-3015.

7. Villines TC, Taylor AJ (2012). Multi-Ethnic Study of Atheroschlerosis Arterial Age Versus Framingham 10-Year or Lifetime Cardiovascular Risk. Am J Cardiol.; 110: 1627-1630.

8. (2010) SCORE2 Working Group and ESC Cardiovascular Risk Collaboration. SCORE2 Risk Prediction Algorithms: New Models to Estimate 10-Year Risk of Cardiovascular Disease in Europe. European Heart Journal. 42:2439-2454.

9. Muntner P, Colantonio LD, Cushman M, Goff DC, Howard G, Howard VJ, Kissela B(2014). Validation of the Atherosclerotic Cardiovascular Disease Pooled Cohort Risk Equations. JAMA.; 311 (14): 1406-1415.

1. 10.Hippisley-Cox J, Coupland C, Vinograndova Y, Robson J, May M, Brindle P (200) Derivation and Validation of QRISK, a New Cardiovacular Disease Risk Score for the United Kingdon: Prospective Oen Cohort Study. EMJ.; 10.1136/bmj.39261.471806.55.

10. Feeman Jr. WE (2020). Enhanced Prediction of the Population at Risk of Atherothrombotic Disease: Back to Framingham. EC Cardiology. 7.3: 1-19.

11. Feeman Jr. W.E (2000). Prediction of Angiographic Stabilization/Regression of Coronary Atherosclerosis by a Risk Factor Graph. J. Cardio. Risk. 7: 415-423.

12. Feeman Jr. W.E. The Bowling Green Study of the Primary and Secondary Prevention of Atherosclerosis: Descriptive Analysis, Findings, Applications and Conclusions. Ohio J. Sci. 92 (5): 153181.

13. Feeman Jr. W.E (1993). The Bowling Green Study of the Primary and Secondary Prevention of Atherosclerotic Disease: Update 1991. Ohio. J. Sci. 94 (4): 105-112.

14. Feeman Jr. W.E (2004). Prediction of the Population at Risk of Atherothrombotic Disease. Experimental and Clinical Cardiology. Winter. 9: (4); 235-241.

15. Friedewald WT, Levy RI, Fredrickson DS (1972). Estimation of the concentration of low-density lipoprotein cholesterol in plasma, without use of the preparative ultracentrifuge. Clin Chem;18:499502.

16. Feeman Jr. W.E (2008). Effect of HDL Measurement Technique on Prediction of Atherothrombotic Disease. Journal of Clinical Lipidology. 2;(5); 401-402.

17. Feeman Jr. WE (2020). Risk Factors for Atherothrombotic Disease: A Suggested Rank Order. EC Cardiology; 7.11: 46-60.

18. Feeman Jr. WE (2013). LDL lowering: Evidence for a Plaque Non-Progression Threshold. Int J Cardiovasc Res. 2: 5.

19. Feeman Jr WE (2021). Angiographic Disease Outcomes When Target Goals of Lipid Modifying Therapy are Not Met: Update. International Journal of Research Studies in Medical and Health Science. 6(17): 1-10. 